\title{
Critical Errors in Inhaler Technique among Children Hospitalized with Asthma
}

\author{
Waheeda Samady, MD, MSCl,2*; Victoria A Rodriguez, MD ${ }^{1,2}$; Ruchi Gupta, MD, MPH',2; \\ Hannah Palac, MS'; Marina Karamanis, BS ${ }^{3}$; Valerie G Press, MD, MPH${ }^{4}$
}

\begin{abstract}
${ }^{1}$ Ann and Robert H. Lurie Children's Hospital of Chicago, Chicago, Illinois; ${ }^{2}$ Northwestern University Feinberg School of Medicine, Chicago, Illinois; ${ }^{3}$ Midwestern University, Downers Grove, Illinois; ${ }^{4}$ University of Chicago, Chicago, Illinois.
\end{abstract}

Past studies have not evaluated inhaler use in hospitalized children with asthma. The objectives of this study were to evaluate inhaler technique in hospitalized pediatric patients with asthma and identify risk factors for improper use. We conducted a prospective cross-sectional study in a tertiary children's hospital for children 2-16 years of age admitted for an asthma exacerbation, and inhaler technique demonstrations were analyzed. Of 113 participants enrolled, $55 \%$ had uncontrolled asthma, and $42 \%$ missed a critical step in inhaler technique. More patients missed a critical step when they used a spacer with mouthpiece instead of a spacer with mask (75\% [51\%-90\%] vs 36\% [27\%-46\%]) and were older (7.8 [6.7-8.9] vs 5.8 [5.1-6.5] years). Patients using the spacer with mouthpiece remained significantly more likely to miss a critical step when adjusting for other clinical covariates (odds ratio 6.95 [1.71-28.23], $P=.007$ ). Hospital-based education may provide teachable moments to address poor proficiency, especially for older children using a mouthpiece. Journal of Hospital Medicine 2018;14:361-365. Published online first April 8, 2019. () 2019 Society of Hospital Medicine

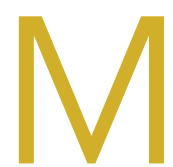

any studies have shown that improved control can be achieved for most children with asthma if inhaled medications are taken correctly and adequately. ${ }^{1-3}$ Drug delivery studies have shown that bioavailability of medication with a pressurized metered-dose inhaler (MDI) improves from $34 \%$ to $83 \%$ with the addition of spacer devices. This difference is largely due to the decrease in oropharyngeal deposition, ${ }^{1,4,5}$ and therefore, the use of a spacer with proper technique has been recommended in all pediatric patients. ${ }^{1,6}$

Poor inhaler technique is common among children. ${ }^{1,7}$ Previous studies of children with asthma have evaluated inhaler technique, primarily in the outpatient and community settings, and reported variable rates of error (from $45 \%$ to $>90 \%$ ). ${ }^{8,9}$ No studies have evaluated children hospitalized with asthma. As these children represent a particularly high-risk group for morbidity and mortality, ${ }_{10}^{10,11}$ the objectives of this study were to assess errors in inhaler technique in hospitalized asthmatic children and identify risk factors for improper use.

\section{METHODS}

As part of a larger interventional study, we conducted a prospective cross-sectional study at a tertiary urban children's hospital. We enrolled a convenience sample of children aged

\footnotetext{
*Corresponding Author: Waheeda Samady, MD; E-mail: wsamady@luriechildrens.org; Telephone: 312-227-4000.

Additional Supporting Information may be found in the online version of this article.
}

Received: November 30, 2018; Revised: February 20, 2019;

Accepted: February 25, 2019

(C) 2019 Society of Hospital Medicine DOI 10.12788/jhm.3195
2-16 years admitted to the inpatient ward with an asthma exacerbation Monday-Friday from 8 AM to 6 PM. Participants were required to have a diagnosis of asthma (an established diagnosis by their primary care provider or meets the National Heart, Lung, and Blood Institute [NHLBI] criteria'), have a consenting adult available, and speak English. Patients were excluded if they had a codiagnosis of an additional respiratory disease (ie, pneumonia), cardiac disease, or sickle cell anemia. The Institutional Review Board approved this study.

We asked caregivers, or children $>10$ years old if they independently use their inhaler, to demonstrate their typical home inhaler technique using a spacer with mask (SM), spacer with mouthpiece (SMP), or no spacer (per their usual home practice). Inhaler technique was scored using a previously validated asthma checklist (Table 1). ${ }^{12}$ Certain steps in the checklist were identified as critical: (Step 1) removing the cap, (Step 3) attaching to a spacer, (Step 7) taking six breaths (SM), and (Step 9) holding breath for five seconds (SMP). Caregivers only were also asked to complete questionnaires assessing their literacy (Brief Health Literacy Screen [BHLS]), confidence (Parent Asthma Management Self-Efficacy scale [PAMSE]), and any barriers to managing their child's asthma (Barriers to Asthma Care). Demographic and medical history information was extracted from the medical chart.

Inhaler technique was evaluated in two ways by comparing: (1) patients who missed more than one critical step with those who missed zero critical steps and (2) patients with an asthma checklist score $<7$ versus $\geq 7$. While there is a lot of variability in how inhaler technique has been measured in past studies, these two markers (75\% of steps and critical errors) were the most common. ${ }^{8}$

We assessed a number of variables to evaluate their association with improper inhaler technique. For categorical vari- 
TABLE 1. Summary of Asthma Checklist and Missed Asthma Checklist Steps by Method $(N=113)$

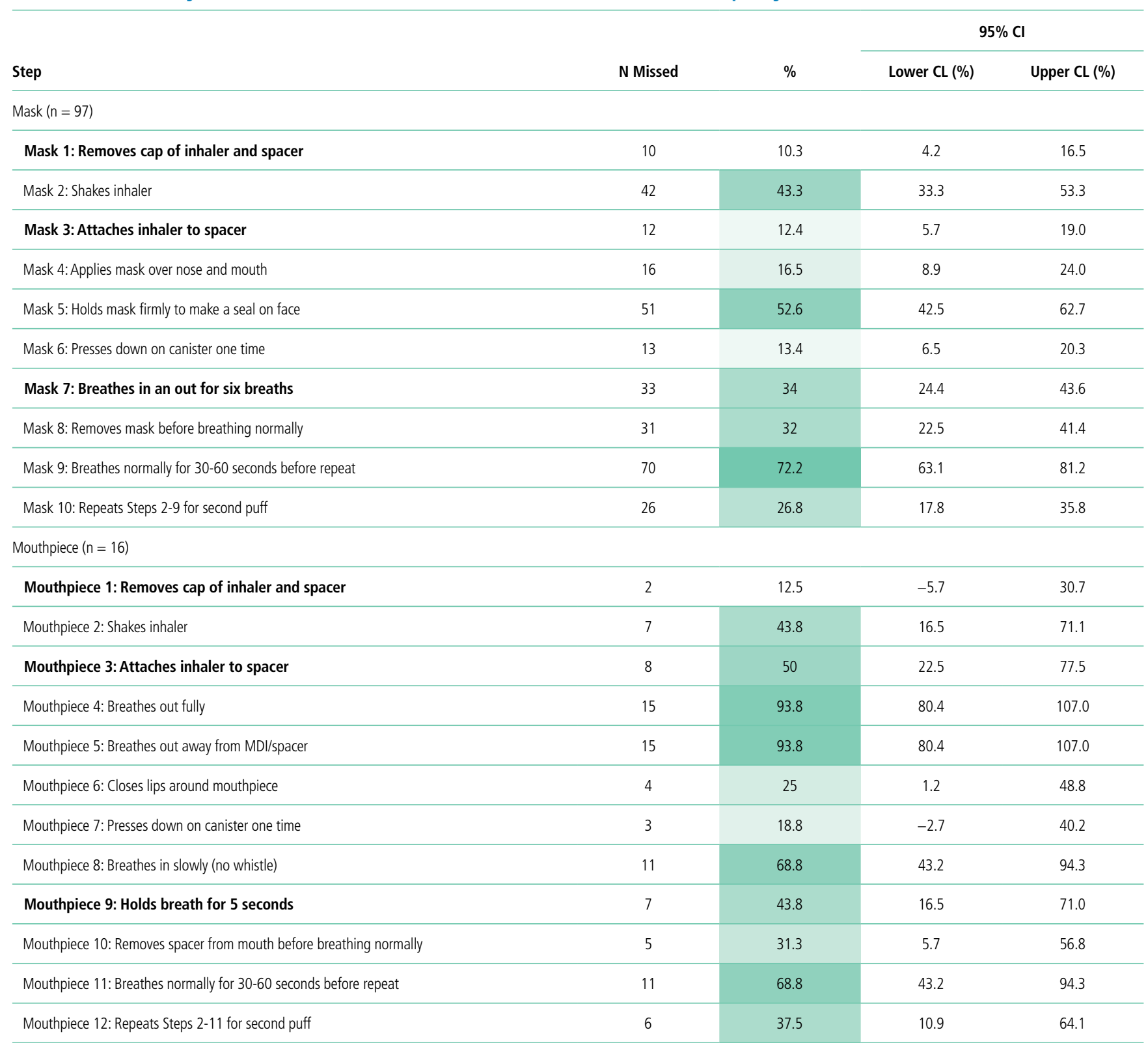

Items in bold represent critical steps. The darker the shading, the higher the percentage of patients who missed the checklist step. Abbreviations: $\mathrm{Cl}$, confidence interval; $\mathrm{CL}$, confidence limit; $\mathrm{MDI}$, metered-dose inhaler.

ables, the association with each outcome was evaluated using relative risks (RRs). Bivariate $P$-values were calculated using chisquare or Fisher's exact tests, as appropriate. Continuous variables were assessed for associations with each outcome using two-sample t-tests. Odds ratios (ORs) and 95\% confidence intervals (Cls) were calculated using logistic regression analyses. Using a model entry criterion of $P<.10$ on univariate tests, variables were entered into a multivariable logistic regression model for each outcome. Full models with all eligible covariates and reduced models selected via a manual backward selection process were evaluated. Two-sided $P$-values $<.05$ were considered statistically significant.

\section{RESULTS}

\section{Participants}

From October 2016 to June 2017, 380 participants were assessed for participation; 215 were excluded for not having a parent available (59\%), not speaking English (27\%), not having an asthma diagnosis (ie, viral wheezing; 14\%), and 52 (14\%) declined to participate. Therefore, a total of 113 participants were enrolled, with demonstrations provided by 100 caregivers and 13 children. The mean age of the patients overall was $6.6 \pm 3.4$ years and over half (55\%) of the participants had uncontrolled asthma (NHLBI criteria $\left.{ }^{1}\right)$. 
TABLE 2. Demographic and Medical History Characteristics by Missed Critical Step ${ }^{\mathrm{a}}$

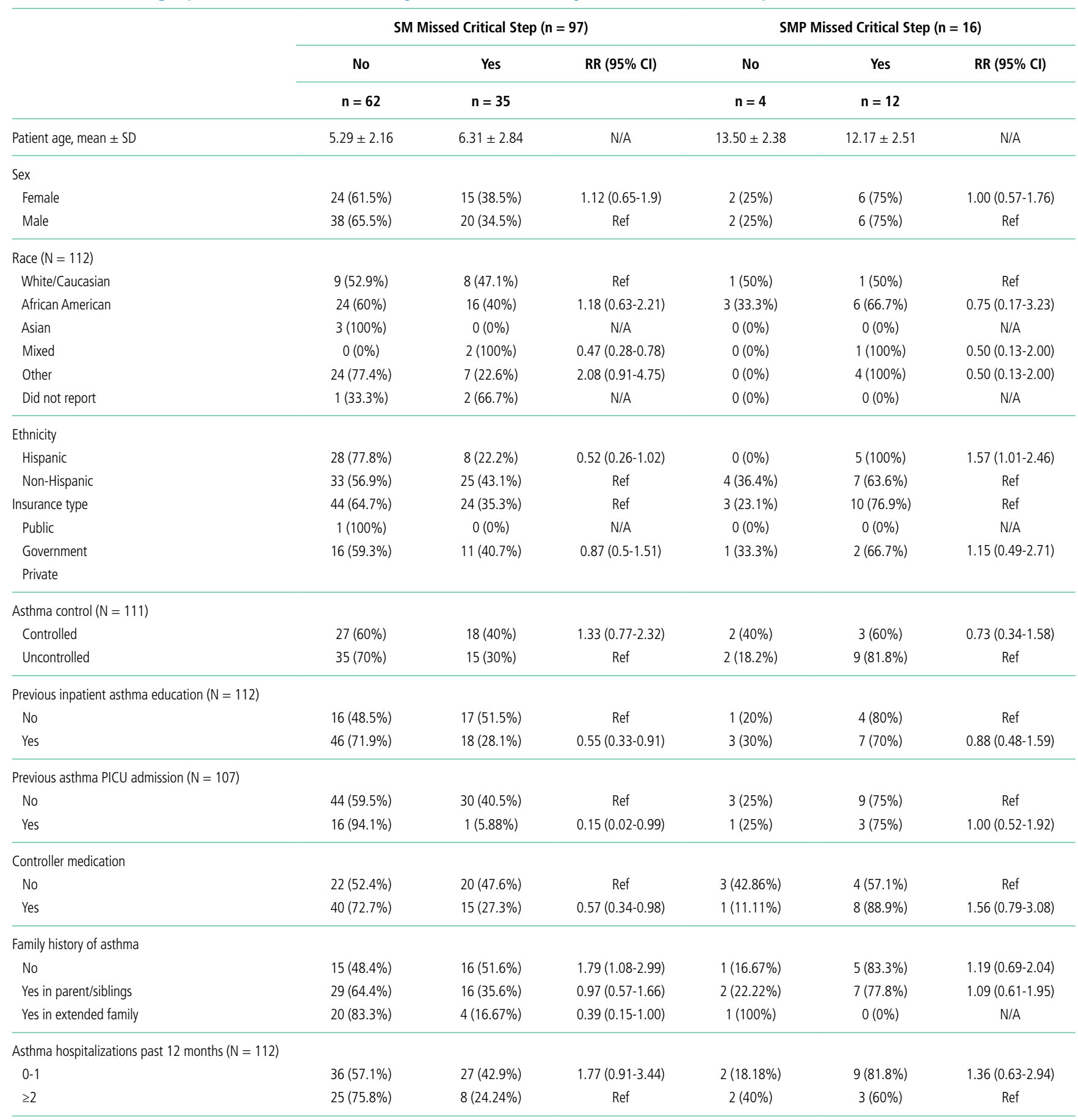

${ }^{a}$ Compared for asthma checklist score $<7$ versus $\geq 7$, no statistically significant difference was found except the women in the mask group were more likely to have score $<7$ ( $46.2 \%$ vs $24.1 \%$ RR $1.91[1.08-3.38])$

Abbreviations: $\mathrm{Cl}$, confidence interval; SD, standard deviation; PICU, pediatric intensive care unit; RR, relative risk; SM, spacer with mask; SMP, spacer with mouthpiece.

\section{Errors in Inhaler Technique}

The mean asthma checklist score was 6.7 (maximum score of 10 for SM and 12 for SMP). A third (35\%) scored $<7$ on the asthma checklist and $42 \%$ of participants missed at least one critical step. Overall, children who missed a critical step were significantly older (7.8 [6.7-8.9] vs 5.8 [5.1-6.5] years; $P=.002)$.
More participants missed a critical step with the SMP than the SM $(75 \%$ [51\%-90\%] vs 36\% [27\%-46\%]; $P=.003)$, and this was the most prominent factor for missing a critical step in the adjusted regression analysis (OR 6.95 [1.71-28.23], $P=.007$ ). The most commonly missed steps were breathing normally for 30 seconds for SM, and for SMP, it was breathing out fully and 
breathing away from the spacer (Table 1). Twenty participants (18\%) did not use a spacer device; these patients were older than those who did use a spacer (mean age 8.5 [6.7-10.4] vs 6.2 [5.6-6.9] years; $P=.005$ ); however, no other significant differences were identified.

\section{Demographic, Medical History, and Socioeconomic Characteristics}

Overall, race, ethnicity, and insurance status did not vary significantly based on asthma checklist score $\geq 7$ or missing a critical step. Patients in the SM group who had received inpatient asthma education during a previous admission, had a history of pediatric intensive care unit (PICU) admission, and had been prescribed a daily controller were less likely to miss a critical step (Table 2). Parental education level varied, with 33\% having a high school degree or less, but was not associated with asthma checklist score or missing critical steps. Parental BHLS and parental confidence (PAMSE) were not significantly associated with inhaler proficiency. However, transportation-related barriers were more common in patients with checklist scores $<7$ and more missed critical steps (OR 1.62 [1.06-2.46]; $P=.02$ ).

\section{DISCUSSION}

Nearly half of the participants in this study missed at least one critical step in inhaler use. In addition, 18\% did not use a spacer when demonstrating their inhaler technique. Despite robust studies demonstrating how asthma education can improve both asthma skills and clinical outcomes, ${ }^{13}$ our study demonstrates that a large gap remains in proper inhaler technique among asthmatic patients presenting for inpatient care. Specifically, in the mouthpiece group, steps related to breathing technique were the most commonly missed. Our results also show that inhaler technique errors were most prominent in the adolescent population, possibly coinciding with the process of transitioning to a mouthpiece and more independence in medication administration. Adolescents may be a high-impact population on which to focus inpatient asthma education. Additionally, we found that a previous PICU admission and previous inpatient asthma education were associated with missing fewer critical steps in inhaler technique. This finding is consistent with those of another study that evaluated inhaler technique in the emergency department and found that previous hospitalization for asthma was inversely related to improper inhaler use (RR 0.55, 95\% Cl 0.36-0.84). ${ }^{14}$ This supports that when provided, inpatient education can increase inhaler administration skills.

Previous studies conducted in the outpatient setting have demonstrated variable rates of inhaler skill, from $0 \%$ to approximately $89 \%$ of children performing all steps of inhalation correctly. ${ }^{8}$ This wide range may be related to variations in the number and definition of critical steps between the different studies. In our study, we highlighted removing the cap, attaching a spacer, and adequate breathing technique as critical steps, because failure to complete them would significantly reduce lung deposition of medication. While past studies did evaluate both MDls and discuss the devices, our study is the first to report difference in problems with technique between SM and SMP. As asthma educational interventions are developed and/or implemented, it is important to stress that different steps in inhaler technique are being missed in those using a mask versus mouthpiece.

The limitations of this study include that it was at a single center with a primarily urban and English-speaking population; however, this study population reflects the racial diversity of pediatric asthma patients. Further studies may explore the reproducibility of these findings at multiple centers and with non-English-speaking families. This study included younger patients than in some previous publications investigating asthma; however, all patients met the criteria for asthma diagnosis and this age range is reflective of patients presenting for inpatient asthma care. Furthermore, because of our daytime research hours, 59\% of patients were excluded because a primary caregiver was not available. It is possible that these families have decreased access to inpatient asthma educators as well and may be another target group for future studies. Finally, a large proportion of parents had a college education or greater in our sample. However, there was no association within our analysis between parental education level and inhaler proficiency.

The findings from this study indicate that continued efforts are needed to establish that inhaler technique is adequate for all families regardless of their educational status or socioeconomic background, especially for adolescents and in the setting of poor asthma control. Furthermore, our findings support that inhaler technique education may be beneficial in the inpatient setting and that acute care settings can provide a valuable "teachable moment." 14,15

\section{CONCLUSION}

Errors in inhaler technique are prevalent in pediatric inpatients with asthma, primarily those using a mouthpiece device. Educational efforts in both inpatient and outpatient settings have the potential to improve drug delivery and therefore asthma control. Inpatient hospitalization may serve as a platform for further studies to investigate innovative educational interventions.

\section{Acknowledgments}

The authors thank Tina Carter for her assistance in the recruitment and data collection and Ashley Hull and Susannah Butters for training the study staff on the use of the asthma checklist.

\footnotetext{
Disclosures: Dr. Gupta receives research grant support from the National Institutes of Health and the United Healthcare Group. Dr. Gupta serves as a consultant for DBV Technology, Aimmune Therapeutics, Kaleo \& BEFORE Brands. Dr. Gupta has received lecture fees/honorariums from the Allergy Asthma Network \& the American College of Asthma, Allergy \& Immunology. Dr. Press reports research support from the Chicago Center for Diabetes Translation Research Pilot and Feasibility Grant, the Bucksbaum Institute for Clinical Excellence Pilot Grant Program, the Academy of Distinguished Medical Educators, the Develop-
} 
ment of Novel Hospital-initiated Care Bundle in Adults Hospitalized for Acute Asthma: the 41st Multicenter Airway Research Collaboration (MARC-41) Study, UCM's Innovation Grant Program, the University of Chicago-Chapin Hall Join Research Fund, the NIH/NHLBI Loan Repayment Program, 1 K23 HL118151 01, NIH NLBHI R03 (RFA-HL-18-025), the George and Carol Abramson Pilot Awards the COPD Foundation Green Shoots Grant, the University of Chicago Women's Board Grant, NIH NHLBI UG1 (RFA-HL-17-009), and the CTSA Pilot Award, outside the submitted work. These disclosures have been reported to Dr. Press' institutional IRB board. Additionally, a management plan is on file that details how to address conflicts such as these which are sources of research support but do not directly support the work at hand. The remaining authors have no conflicts of interest relevant to the article to disclose.

Funding: This study was funded by internal grants from Ann and Robert H. Lurie Children's Hospital of Chicago. Dr. Press was funded by a K23HL118151.

\section{References}

1. Expert Panel Report 3: guidelines for the diagnosis and management of asthma: full report. Washington, DC: US Department of Health and Human Services, National Institutes of Health, National Heart, Lung, and Blood Institute; 2007.

2. Hekking PP, Wener RR, Amelink M, Zwinderman AH, Bouvy ML, Bel EH. The prevalence of severe refractory asthma. J Allergy Clin Immunol. 2015;135(4):896-902. doi: 10.1016/j.jaci.2014.08.042.

3. Peters SP, Ferguson G, Deniz Y, Reisner C. Uncontrolled asthma: a review of the prevalence, disease burden and options for treatment. Respir Med. 2006;100(7):1139-1151. doi: 10.1016/j.rmed.2006.03.031.

4. Dickens GR, Wermeling DP, Matheny $\mathrm{CJ}$, et al. Pharmacokinetics of $\mathrm{fl}$ unisolide administered via metered dose inhaler with and without a spacer device and following oral administration. Ann Allergy Asthma Immunol. 2000;84(5):528-532. doi: 10.1016/S1081-1206(10)62517-3.

5. Nikander K, Nicholls C, Denyer J, Pritchard J. The evolution of spacers and valved holding chambers. J Aerosol Med Pulm Drug Deliv. 2014;27(1):S4-
S23. doi: 10.1089/jamp.2013.1076.

6. Rubin BK, Fink JB. The delivery of inhaled medication to the young child. Pediatr Clin North Am. 2003;50(3):717-731. doi:10.1016/S0031-3955(03)00049-X.

7. Roland NJ, Bhalla RK, Earis J. The local side effects of inhaled corticosteroids: current understanding and review of the literature. Chest. 2004;126(1):213219. doi: 10.1378/chest.126.1.213.

8. Gillette C, Rockich-Winston N, Kuhn JA, Flesher S, Shepherd M. Inhaler technique in children with asthma: a systematic review. Acad Pediatr. 2016;16(7):605-615. doi: 10.1016/j.acap.2016.04.006.

9. Pappalardo AA, Karavolos K, Martin MA. What really happens in the home: the medication environment of urban, minority youth. J Allergy Clin Immunol Pract. 2017;5(3):764-770. doi: 10.1016/j.jaip.2016.09.046.

10. Crane J, Pearce N, Burgess C, Woodman K, Robson B, Beasley R. Markers of risk of asthma death or readmission in the 12 months following a hospital admission for asthma. Int J Epidemiol. 1992;21(4):737-744. doi: 10.1093/ ije/21.4.737.

11. Turner MO, Noertjojo K, Vedal S, Bai T, Crump S, Fitzgerald JM. Risk factors for near-fatal asthma. A case-control study in hospitalized patients with asthma. Am J Respir Crit Care Med. 1998;157(6 Pt 1):1804-1809. doi: 10.1164/ ajrccm.157.6.9708092.

12. Press VG, Arora VM, Shah LM, et al. Misuse of respiratory inhalers in hospitalized patients with asthma or COPD. J Gen Intern Med. 2011;26(6):635-642. doi: 10.1007/s11606-010-1624-2.

13. Guevara JP, Wolf FM, Grum CM, Clark NM. Effects of educational interventions for self management of asthma in children and adolescents: systematic review and meta-analysis. BMJ. 2003;326(7402):1308-1309. doi: 10.1136/ bmj.326.7402.1308.

14. Scarfone RJ, Capraro GA, Zorc JJ, Zhao H. Demonstrated use of metered-dose inhalers and peak flow meters by children and adolescents with acute asthma exacerbations. Arch Pediatr Adolesc Med. 2002;156(4):378383. doi: 10.1001/archpedi.156.4.378.

15. Sockrider MM, Abramson S, Brooks E, et al. Delivering tailored asthma family education in a pediatric emergency department setting: a pilot study. Pediatrics. 2006;117(4 Pt 2):S135-144. doi: 10.1542/peds.2005-2000K. 